\title{
SIMULASI NUMERIK KENDALI KAPAL CEPAT TAK BERAWAK DUA PROPELLER TANPA RUDDER
}

\author{
Muhammad Arifudin Lukmana ${ }^{1 \otimes}$, Fahrudin $^{2}$, Qisthi Al Hazmi Hidayatur \\ Rohman $^{3}$, Noverdo Saputra ${ }^{4}$ \\ ${ }^{1,2}$ Teknik Mesin, Universitas Pembangunan Nasional Veteran Jakarta, Jakarta Selatan, 12450. \\ ${ }^{3}$ Teknik Elektro, Universitas Pembangunan Nasional Veteran Jakarta, Jakarta Selatan, 12450. \\ ${ }^{4}$ Teknik Perkapalan, Universitas Pembangunan Nasional Veteran Jakarta, Jakarta Selatan, 12450. \\ $\otimes_{e \text {-mail : arifudin@upnvj.ac.id }}$
}

\begin{abstract}
This paper discusses the simulation of automation control and hull manufacturing on a fast boat. This highspeed boat that will be carried out for fish mapping. This study uses a numerical simulation to predict its motion. The experiment was carried out 3 times in forward motion, and 3 times in turn motion. The ship's time and movement in ideal conditions will be recorded for each experiment. With the PID value for forward overshoot with values such as: $8.94 \%, 30.86 \%$, and $40.60 \%$, while turning overshoot is obtained, among others: $25.77 \%, 49.82 \%$, and $61.15 \%$ Then the advanced settling time obtained includes: 0.91 seconds, 3.84 seconds, and 5.31 seconds. The settling time for turns is: 1,022 seconds, 0.85 seconds, and 0.84 seconds These values are obtained from the simulation graph of the three-dof formulas for surge, sway, yaw.
\end{abstract}

Keywords : Fast ship, automation, simulation, motion.

\begin{abstract}
Abstrak
Artikel ini membahas mengenai simulasi dari kendali otomatis dan pembuatan lambung kapal cepat. Kapal berkecepatan tinggi ini akan digunakan untuk pemetaan ikan. Simulasi menggunakan komputasi numerik untuk mengetahui pergerakannya. Eksperimen dilakukan sebanyak tiga kali untuk gerakan lurus dan tiga kali untuk gerakan belok. Masing-masing eksperimen akan dicatat waktu dan pergerakannya pada kondisi ideal. Nilai PID untuk overshoot saat gerakan maju adalah: 8.94\%, $30.86 \%$, and $40.60 \%$, sedangkan saat gerakan belok terdapat overshoot: $25.77 \%$, $49.82 \%$, and $61.15 \%$. Sedangkan settling time saat gerakan maju: 0.91 detik, 3.84 detik, and 5.31 detik. Settling time saat gerakan belok adalah: 1,022 detik, 0.85 detik, dan 0.84 detik. Nilai-nilai ini didapatkan dari grafik simulasi dari tiga persamaan derajat kebebasan: surge, sway dan yaw.
\end{abstract}

Kata kunci : kapal cepat, otomasi, simulasi, gerak.

\section{Pendahuluan}

Selama beberapa tahun belakang ini robot yang sedang populer untuk perairan adalah robot kapal tanpa awak atau Unmanned Surface Vehicle (USV), yaitu robot yang bergerak di atas permukaan air. USV ini memungkinkan untuk diprogram dengan dengan kecerdasan buatan. Namun sebelum menerapkan teknologi kecerdasan buatan, prediksi gerakan fisik atau pemodelan dari sebuah platform sudah harus diketahui. Pemodelan berisi kinematika, kinetika, penyederhanaan model dan identifikasi model [1]. Bergantung dari misi yang akan dijalankan, spesifikasi setiap USV akan berbeda. Namun tentunya kelebihan dari sebuah USV adalah kecerdasannya [2]. Misi yang akan dijalankan adalah pemetaan ikan.

Sebuah USV untuk misi pemetaan ikan akan membutuhkan beberapa perintah dasar untuk bermanuver. Pada artikel ini akan dibahas pilihan manuver dasar sebagai final control element dari system. Mengingat USV ini tidak memiliki rudder, perintah dasar ini adalah maju dan belok berdasarkan kombinasi antara dua propeller [3]. Batasan yang berlaku adalah keadaan lingkungan ideal: air tenang dan tidak terdapat angin.

Brushless Motor 
Brushless DC Motor termasuk kedalam jenis motor sinkron. Artinya medan magnet yang dihasilkan oleh stator dan medan magnet yang dihasilkan oleh rotor berputar pada frekuensi yang sama. Motor BLDC tidak mengalami slip seperti yang terjadi pada motor induksi biasa. Motor jenis ini mempunyai magnet permanen pada bagian rotor dan elektromagnet pada bagian stator. Setelah itu, dengan menggunakan sebuah rangkaian sederhana (simple computer system), maka kita dapat merubah arus di elektromagnet ketika bagian rotornya berputar.

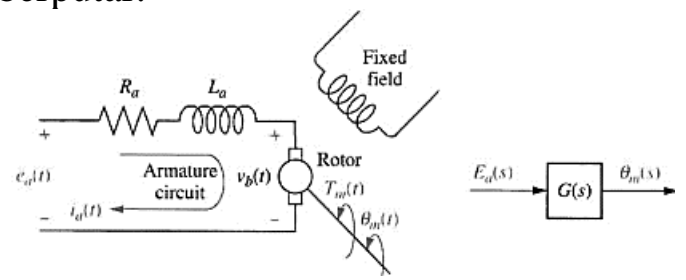

Gambar 1. Skema dan Blok diagram sebuah motor listrik

Sekarang untuk menemukan $T_{m}(s)$ dalam hal $\theta_{m}(s)$ jika ingin memisahkan input dan variabel keluaran dan dapatkan fungsi transfer, $\theta_{m}(s) / E_{a}(s)$

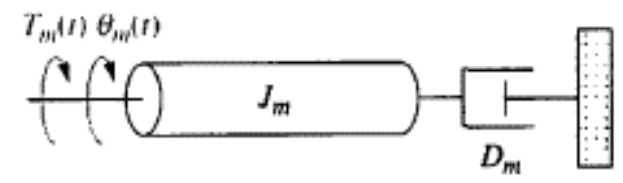

Gambar 2. Pemodelan mekanis pada Motor

Persamaan fungsi transfer yang diinginkan, $\theta_{m}(s) / E_{a}(s)$, ditentukan dengan persamaan berikut :

$\frac{\theta_{m}(s)}{E_{a}(s)}=\frac{K_{t} /\left(R_{a} J_{m}\right)}{s\left[s+\frac{1}{J_{m}}\left(D_{m}+\frac{K_{t} K_{b}}{R_{a}}\right]\right.}$

Meskipun bentuk Persamaan. Persamaan diatas dapat dibuat menjadi lebih relatif sederhana [4], yaitu :

$\frac{\theta_{\mathrm{m}}(\mathrm{s})}{\mathrm{E}_{\mathrm{a}}(\mathrm{s})}=\frac{\mathrm{K}}{\mathrm{s}(\mathrm{s}+\alpha)}$

\section{Kendali P, I dan D}

Pengendalian kombinasi kontrol P, I dan D maka, masing-masing kelebihannya dapat digabungkan untuk mendapatkan kontrol ideal [5].

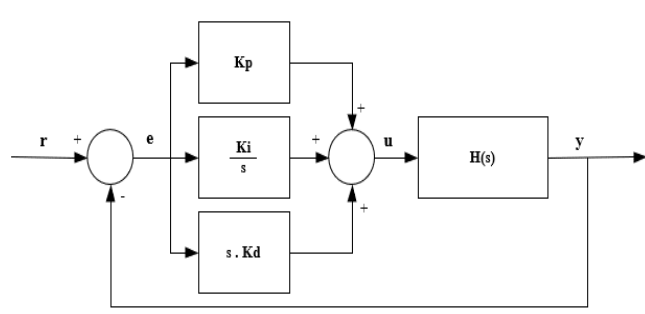

Gambar 3. Kontrol PID

\section{Pemodelan Dinamik Tiga Derajat} Kebebasan

Persamaan gerak kapal USV menggunakan sumbu tubuh sebagai sistem referensi. Sumbu X positif berada di sepanjang sumbu longitudinal ke arah depan; sumbu $\mathrm{Z}$ positif berada di sepanjang sumbu vertikal ke arah bawah, yaitu, sepanjang bidang simetri ke arah bawah, dan tegak lurus terhadap sumbu $\mathrm{X}$; dan sumbu Y positif adalah sepanjang sumbu lateral ke kanan, yaitu, tegak lurus terhadap bidang simetri, dan tegak lurus terhadap sumbu X dan Z. [6]

\section{Kinematika}

Model tiga-DOF untuk menggambarkan gerakan planar USV dalam surge, sway dan yaw, dapat ditunjukan pada gambar [7].

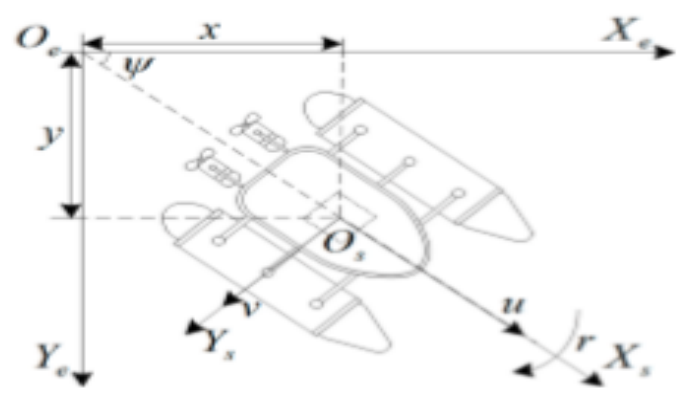

Gambar 4. Diagram skematik tiga DOF dari USV

Untuk menentukan persamaan gerak, dua sistem koordinat referensi dipertimbangkan: kerangka inersia atau tetap ke bumi $O_{e} X_{e} Y_{e}$ yang dapat dianggap bertepatan dengan koordinat tetap $U S V$ dalam beberapa kondisi awal dan kerangka tubuh tetap yaitu $O_{S} X_{S} Y_{S}$ pada Gambar 4. Karena gerakan bumi hampir tidak mempengaruhi $U S V$ 
(berbeda dari kendaraan udara), rangka bumi-tetap $O_{e} X_{e} Y_{e}$ dapat dianggap inersia. Tubuh sumbu $O_{S} X_{S}$ dan $O_{S} Y_{S}$ bertepatan dengan sumbu utama inersia dan biasanya didefinisikan sebagai berikut: $O_{S} X_{S}$ adalah sumbu longitudinal (diarahkan dari belakang ke depan); $O_{S} Y_{S}$ adalah sumbu transversal (diarahkan ke kanan).

Model kinematik USV khas dalam gerakan planar dan tanpa adanya gangguan dapat dinyatakan sebagai:

$$
\dot{\eta}=\mathrm{J}(\eta) v
$$

di mana $\boldsymbol{\eta}=\left[\begin{array}{lll}\boldsymbol{x} & \boldsymbol{y} & \boldsymbol{\psi}\end{array}\right]^{\mathbf{T}}$ adalah posisi (x, y) dan yaw $(\psi)$ dari $U S V$ dalam bingkai tetap di bumi,. $\dot{\boldsymbol{\eta}}=$ $\left[\begin{array}{lll}\dot{x} & \dot{\boldsymbol{y}} & \dot{\boldsymbol{\psi}}\end{array}\right]^{\mathbf{T}} \quad$ menggambarkan kecepatan linier kendaraan utara $(\dot{\boldsymbol{x}})$, Timur $(\dot{\boldsymbol{y}})$, dan sudut sumbu Z $(\dot{\boldsymbol{\psi}})$ dalam kerangka tetap bumi, $v=\left[\begin{array}{lll}u & v & r\end{array}\right]^{\mathbf{T}}$ adalah surge velocity $(\mathrm{u})$, sway velocity $(v)$ dan yaw rate $(r)$ dan matriks transformasi $\mathbf{J}(\eta)$, terkait dengan yaw $(\boldsymbol{\psi})$, diberikan oleh

$$
J(\eta)=\left[\begin{array}{ccc}
\cos \psi & -\sin \psi & 0 \\
\sin \psi & \cos \psi & 0 \\
0 & 0 & 1
\end{array}\right]
$$

\section{Kinetik}

Berdasarkan asumsi-asumsi ini, model kinetik dapat disederhanakan

$$
\begin{gathered}
M \dot{v}+C(v) v+D(v) v=\tau \\
M=\left[\begin{array}{ccc}
m-X_{\dot{u}} & 0 & 0 \\
0 & m-Y_{\dot{v}} & 0 \\
0 & 0 & I_{z}-N_{\dot{r}}
\end{array}\right] \ldots(5) \\
\boldsymbol{C}(\boldsymbol{v})= \\
{\left[\begin{array}{ccc}
\mathbf{0} & \mathbf{0} & -\left(\boldsymbol{m}-\boldsymbol{Y}_{\dot{\boldsymbol{v}}}\right) \boldsymbol{v} \\
\mathbf{0} & \mathbf{0} & \left(\boldsymbol{m}-\boldsymbol{X}_{\dot{\boldsymbol{u}}}\right) \boldsymbol{u} \\
\left(\boldsymbol{m}-\boldsymbol{Y}_{\dot{\boldsymbol{v}}}\right) \boldsymbol{v} & -\left(\boldsymbol{m}-\boldsymbol{X}_{\dot{\boldsymbol{u}}}\right) \boldsymbol{u} & \mathbf{0}
\end{array}\right]}
\end{gathered}
$$

$$
D(v)=D=-\left[\begin{array}{ccc}
X_{u} & 0 & 0 \\
\mathbf{0} & Y_{v} & 0 \\
\mathbf{0} & \mathbf{0} & \boldsymbol{N}_{\boldsymbol{r}}
\end{array}\right]
$$

Oleh karena itu, model tiga DOF dari $U S V$ dengan pendorong ganda tanpa kemudi dapat diekspresikan oleh

$$
\begin{gathered}
\dot{\boldsymbol{\eta}}=\mathrm{J}(\boldsymbol{\eta}) \boldsymbol{v} \\
\boldsymbol{M} \dot{\boldsymbol{v}}+\boldsymbol{C}(\boldsymbol{v}) \boldsymbol{v}+\boldsymbol{D}(\boldsymbol{v}) \boldsymbol{v}=\boldsymbol{\tau}
\end{gathered}
$$

Untuk menyederhanakan desain pengontrol, kami membuat asumsi berikut dari model kinetik:

$$
\begin{gathered}
\dot{x}=u \cos \psi-v \sin \psi \\
\dot{y}=u \sin \psi+v \cos \psi \\
\dot{\psi}=r
\end{gathered}
$$

$$
\begin{gathered}
\left(m-X_{\dot{u}}\right) \dot{u}-\left(m-Y_{\dot{v}}\right) v r+X_{u} u=X_{P 1}+ \\
X_{P 2} \\
\left(m-Y_{\dot{v}}\right) \dot{v}+\left(m-X_{\dot{u}}\right) u r+Y_{v} v=0 \\
\left(I_{z}-N_{\dot{r}}\right) \dot{r}-\left(\left(m-X_{\dot{u}}\right)-\left(m-Y_{\dot{v}}\right)\right) \\
u v+N_{r} r=\left(X_{P 1}-X_{P 2}\right) \cdot d_{p} \quad \ldots(10)
\end{gathered}
$$

\section{Persamaan Dinamika Gerak Kapal}

Propeller yang digunakan adalah dua buah tanpa adanya rudder. Bentuk aktual dua propeller ini dapat dilihat pada Gambar 5.

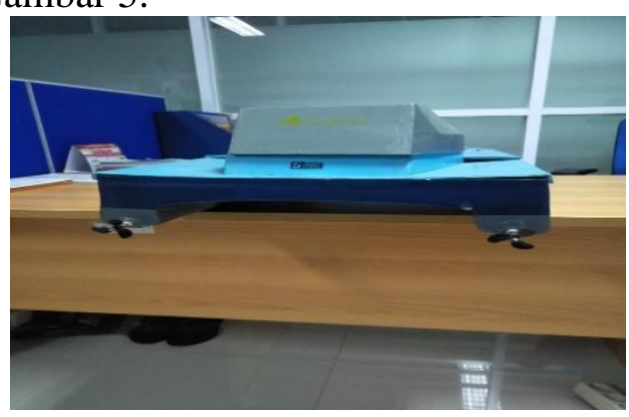

Gambar 5. Propeller kapal aktual

Propeller thrust dapat dinyatakan sebagai sebagai berikut.

$$
X_{P}=c V n+d|n| n
$$

Dari rumus propeller thrust berikut terdapat parameter-parameter yang sudah ditentukan, sehingga kita mencari nilai dari variabel $c$ dan $d$ [7]. 
Muhammad Arifudin Lukmana, dkk., Simulasi Numerik Kendali...

$$
\begin{aligned}
& \boldsymbol{c}=\frac{\tilde{\boldsymbol{c}}\left(\boldsymbol{m}-X_{\dot{u}}\right)}{2}= \\
& \frac{-6.402 \times 10^{-6} \mathbf{s}^{-1} \cdot \mathrm{RPS}^{-1} \cdot \mathrm{kg}^{-1}(\mathbf{k g}-(\mathbf{0 . 0 0 5}) \mathrm{kg})}{\mathbf{2}} \\
& =-\mathbf{1 . 6 0} \times \mathbf{1 0} \mathbf{1 0}^{-\mathbf{5}} \mathbf{s}^{-\mathbf{1}} \cdot \mathbf{R P S}^{-\mathbf{1}} \cdot \mathbf{k g}^{-1} \\
& d=\frac{\tilde{d}\left(\mathrm{~m}-X_{\dot{u}}\right)}{2}= \\
& =\frac{2.014 \times 10^{-4} \mathrm{~ms}^{-2} \cdot \mathrm{RPS}^{-2} \cdot \mathrm{kg}^{-1}(5 \mathrm{~kg}-(0.005) \mathrm{kg})}{2} \\
& =5.04 \times 10^{-4} \mathrm{~ms}^{-2} \cdot \mathrm{RPS}^{-2} \cdot \mathrm{kg}^{-1}
\end{aligned}
$$

\begin{tabular}{|c|c|c|}
\hline Lambang & Parameter & $\begin{array}{c}\begin{array}{c}\text { Nilai dan } \\
\text { satuan }\end{array} \\
\end{array}$ \\
\hline $\mathbf{J}$ & $\begin{array}{l}\text { Momen inersia } \\
\text { rotor }\end{array}$ & $\begin{array}{c}0.01 \\
\text { Kg.m }\end{array}$ \\
\hline B & $\begin{array}{c}\text { Konstanta } \\
\text { gesekan motor }\end{array}$ & 0.1 N.m.s \\
\hline K & Konstanta motor & 0.01 N.m \\
\hline $\mathrm{R}$ & Hambatan listrik & $1 \mathrm{Ohm}$ \\
\hline $\mathrm{L}$ & Induktansi listrik & $0.5 \mathrm{H}$ \\
\hline
\end{tabular}

Tabel 1. Parameter Motor

\section{Metode Penelitian}

Berikut adalah metodologi penelitian yang digunakan dalam artikel ini.

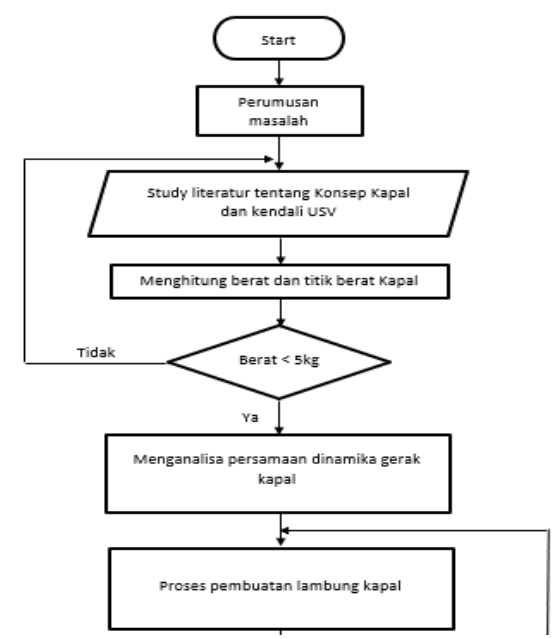

Gambar 6a. Diagram alir penelitian (awal)

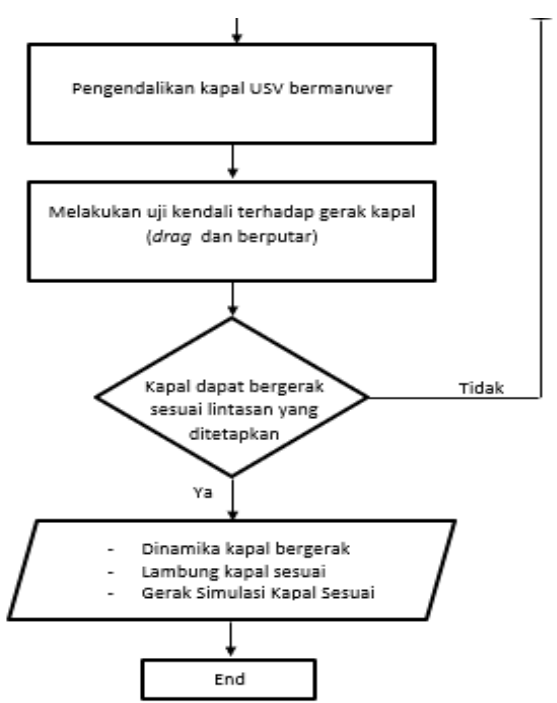

Gambar 6b. Diagram alir penelitian (lanjutan)

Sistem Gerak USV dalam perangkat lunak numerik dapat dilihat pada Gambar 7. Input ada pada bagian kiri dan output pada bagian kanan. Terdapat dua input yang diberikan (perintah maju dan belok) sedangkan pada bagian output yang diamati adalah kelajuan maju dan beloknya saja.

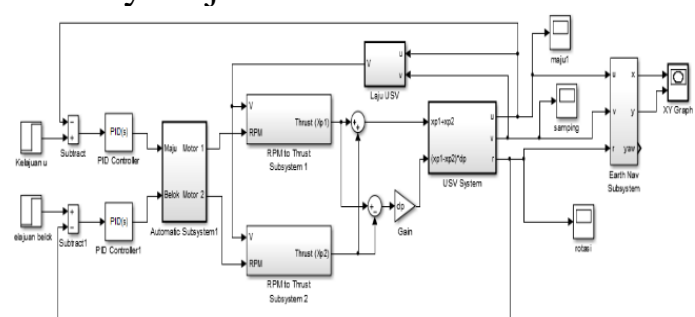

Gambar 7. Blok diagram USV simulation system

\section{Perintah pada USV}

Perintah yang akan diberikan oleh sistem autonomous adalah maju atau belok. Perintah ini didefinisikan sebagai perintah kelajuan. Pada gerakan maju, satuan yang digunakan adalah meter per detik. Sedangkan pada gerakan belok, radian per detik. Gerakan belok mengikuti aturan tangan kanan dengan sumbu putar mengarah ke atas. Ilustrasi mengenai gerakan ini ada pada gambar 8 .

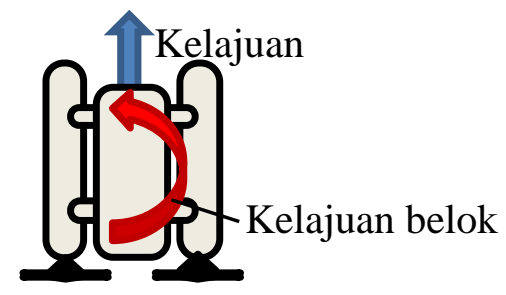


Gambar 8. Ilustrasi kelajuan maju dan kelajuan belok.

\section{Hasil dan Pembahasan}

Nilai PID yang didapatkan adalah menggunakan metode trial-error dengan estimasi pendahuluan dari fitur autotuning. Nilai PID yang digunakan tertera pada Tabel 2 .

\begin{tabular}{lc}
\hline \multicolumn{1}{c}{ Kendali Roll } & Nilai \\
\hline Proportional & 100 \\
Integral & 100 \\
Derivative & 15 \\
\hline
\end{tabular}

Tabel 2. Nilai PID

Pengukuran kualitas gerakan kapal dengan menggunakan persentase overshoot. Adapun rumus yang digunakan untuk mengukur overshoot pada grafik:

$\% O S=\frac{C_{\text {Max }}-C_{\text {Final }}}{C_{\text {Final }}} \times 100$

Dimana :

$\mathrm{C}_{\text {Max }}=$ Nilai terbesar

$\mathrm{C}_{\text {Final }}=$ Nilai Final yang diperoleh

\section{Percobaan Gerak Maju}

Nilai yang kami gunakan pada kelajuan maju adalah 1; 4 dan 7 meter per detik. Sedangkan untuk kelajuan belok adalah 1; 1,5 dan 2 radian per detik. Hasil respon USV dapat dilihat pada gambar di bawah ini.

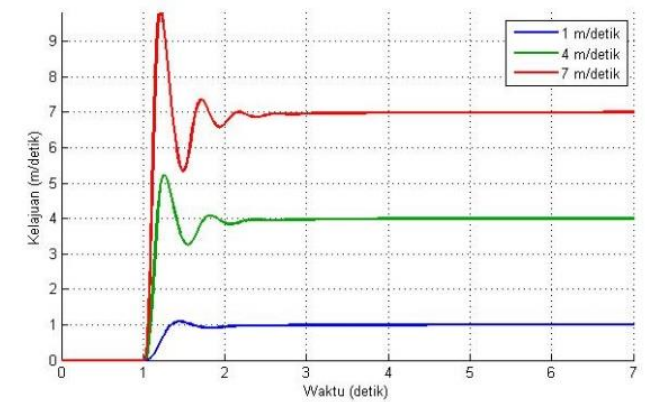

Gambar 9. Grafik kelajuan maju $1 \mathrm{~m} / \mathrm{s} ; 4$ m/s; 7 $\mathrm{m} / \mathrm{s}$
Tabel 3. Rangkuman nilai settling time dan overshoot pada perintah maju

\begin{tabular}{|c|c|c|c|c|c|}
\hline Percobaan & $P$ & $I$ & $D$ & $\begin{array}{c}\text { Settling } \\
\text { time }\end{array}$ & $\begin{array}{c}\text { Over } \\
\text { shoot }\end{array}$ \\
\hline $\begin{array}{ll}\text { (kelajuan } \\
\text { maju } & 1 \\
\text { m/det) } & \\
\end{array}$ & 100 & 100 & 15 & $1.68 \mathrm{~s}$ & $9 \%$ \\
\hline $\begin{array}{l}\text { (kelajuan } \\
\text { maju } \\
\text { m/det) }\end{array}$ & 100 & 100 & 15 & $1.22 \mathrm{~s}$ & $30,475 \%$ \\
\hline $\begin{array}{l}\text { (kelajuan } \\
\text { maju } \\
\text { m/det) }\end{array}$ & 100 & 100 & 15 & $1,07 \mathrm{~s}$ & $40,34 \%$ \\
\hline
\end{tabular}

\section{Percobaan Gerak Belok}

Pada percobaan ini perintah maju terdapat tiga variasi: $1 ; 1,5$ dan 2 meter per detik. Sedangkan untuk belok, kelajuan yang digunakan adalah 1 radian per detik saja. Pemilihan nilai tersebut disebabkan karena respon radius pada Gambar 11 yang cukup besar apa bila nilai kelajuan belok atau maju terlalu besar. Gambar 10 (a) dan (b) adalah tiga percobaan yang dilakukan bersamaan namun yang dilihat adalah dua hal berbeda. Subsystem belok dan sub sistem maju diamati satu persatu.

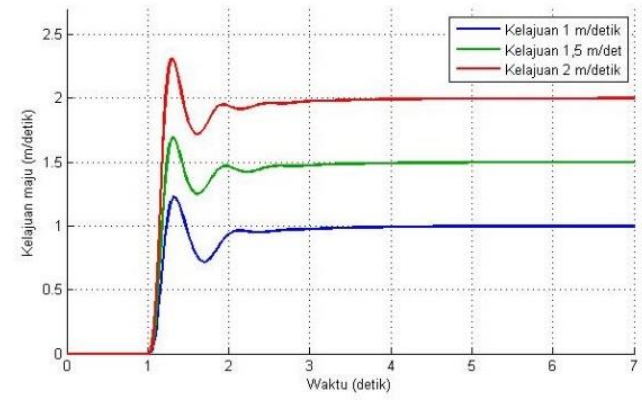

(a)

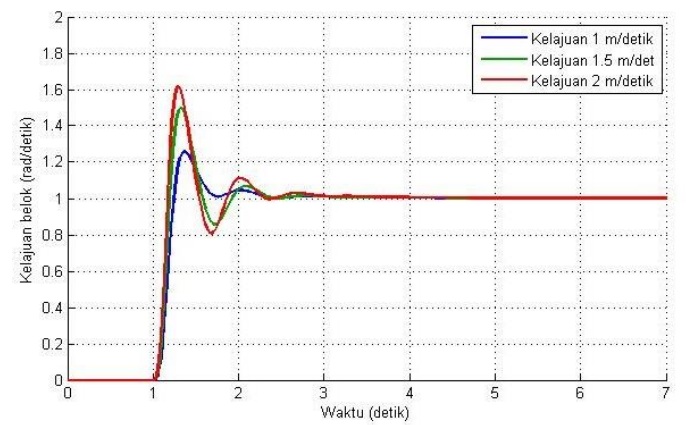

(b)

Gambar 10. Grafik gerak lurus (a) dan grafik kelajuan belok (b), dengan kelajuan belok $1 \mathrm{rad} / \mathrm{s}$ dan kelajuan maju $1 \mathrm{~m} / \mathrm{s} ; 1,5 \mathrm{~m} / \mathrm{s} ; 2 \mathrm{~m} / \mathrm{s}$ 
Dari hasil percobaan-percobaan di atas dapat diringkas kedalam tabel berikut:

Tabel 4. Rangkuman nilai settling time dan overshoot pada perintah maju dan belok

\begin{tabular}{cccccc} 
Sistem & $P$ & $I$ & $D$ & $\begin{array}{c}\text { Settling } \\
\text { time }\end{array}$ & $\begin{array}{c}\text { Over } \\
\text { shoot }\end{array}$ \\
\hline
\end{tabular}

Percobaan 1 (kelajuan: maju 1 m/det dan belok $1 \mathrm{rad} /$ det)

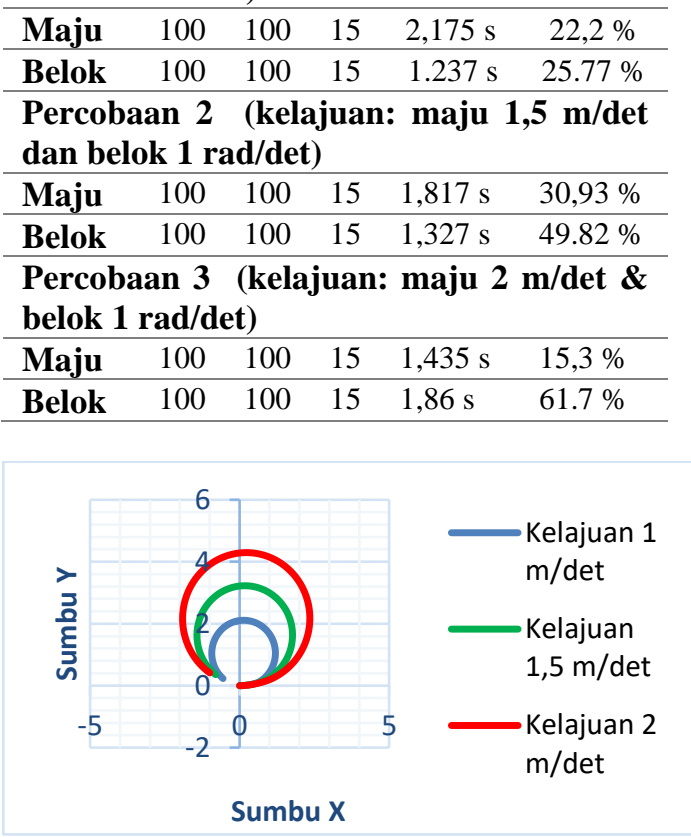

Gambar 11. Grafik Trayektori kapal saat laju belok $1 \mathrm{rad} /$ detik dengan variasi perintah maju

\section{Analisis}

Dari hasil percobaan di atas kita dapat mengambil perkiraan radius belok yang sesuai dengan skenario yang ingin dijalankan. Misalnya untuk radius belok $2 \mathrm{~m}$, maka kita atur kelajuan maju pada $1 \mathrm{~m} / \mathrm{s}$ dan belok pada $1 \mathrm{~m} / \mathrm{s}$. untuk kecepatan yang lebih, kita dapat gunakan nilai yang lebih tinggi. Namun jika menggunakan kecepatan yang tinggi berisiko tidak stabil karena tingginya nilai overshoot. Pada kondisi air tenang tentu ini tidak akan ada masalah, namun jika air bergelombang akan mengakibatkan tidak stabil.

Untuk pengembangan selanjutnya, perlu diberikan sebuah perintah berurutan kepada $U S V$ dapat dinilai manuvernya. Baik perintah zig-zag, path following atau path maneuvering.

\section{KESIMPULAN}

Dari pembahasan hasil dapat disimpulkan sebagai berikut:

1. Respon gerak USV sudah sesuai dengan skenario misinya.

2. Nilai PID sebesar $P=100, I=100$, dan $\mathrm{D}=15$.

3. Skenario belok dengan radius 2 meter, maka perintah pada input adalah maju $1 \mathrm{~m} / \mathrm{s}$ dan belok $1 \mathrm{~m} / \mathrm{s}$. Untuk radius yang lebih besar, dapat menggunakan perintah maju yang lebih cepat lagi.

4. Respon subsystem maju percobaan gerak maju adalah semakin tinggi nilai kelajuannya, settling time semakin cepat, namun persentase overshoot meningkat

5. Respon subsystem belok pada percobaan gerak belok adalah semakin tinggi nilai kelajuannya, settling time dan persentase overshoot meningkat.

\section{Ucapan Terima kasih}

Terimakasih tim penulis ucapkan kepada UPN Veteran Jakarta. Penelitian ini terwujud karena adanya hibah penelitian internal kampus dengan skema Riset Dosen Pemula.

\section{Daftar Pustaka}

[1] J. Liu, J. Luo, J. Cui, and Y. Peng, "Trajectory Tracking Control of Underactuated USV with Model Perturbation and External Interference," MATEC Web Conf., vol. 77, no. 15, pp. 0-5, 2016, doi: 10.1051/matecconf/20167709009.

[2] R. jian Yan, S. Pang, H. bing Sun, and Y. jie Pang, "Development and missions of unmanned surface vehicle," J. Mar. Sci. Appl., vol. 9, no. 4, pp. 451-457, 2010, doi: 10.1007/s11804-010-1033-2.

[3] S. K. Sharma, W. Naeem, and R. Sutton, "An autopilot based on a local control network design for an unmanned surface vehicle," $J$. Navig., vol. 65, no. 2, pp. 281-301, 
2012 ,

doi:

10.1017/S0373463311000701.

[4] N. S. Nise, "Control system engineering, john wiley \& sons," Inc, New York, 2011.

[5] E. Pitowarno, "Robotika desain, kontrol, dan kecerdasan buatan," Yogyakarta Andi, 2006.

[6] O. Sutresman, R. Syam, and S. Asmal, "Controlling Unmanned
Surface Vehicle Rocket using GPS Tracking Method," Int. J. Technol, vol. 8, pp. 709-718, 2017.

[7] C. Li et al., "Modeling and experimental testing of an unmanned surface vehicle with rudderless double thrusters," Sensors (Switzerland), vol. 19, no. 9, 2019, doi: 10.3390/s19092051. 